\title{
Investigation of flow parameters in a cylindrical pebble bed and in a model of a fuel assembly with microfuels
}

\author{
Yuliya Smorchkova*, Alexander Varava, Alexey Dedov, Alexander Zakharenkov, Alexander \\ Komov, and Alexander Borozdin
}

National Research University "MPEI", Krasnokazarmennaya 14, 111250 Moscow, Russia

\begin{abstract}
The results of an experimental study of the hydrodynamics and heat transfer of a pebble bed in a cylindrical channel and in a model of a fuel assembly with microfuels (FA MT) with a cross flow of a coolant are presented. Data on the temperature distribution along the height and the pebble radius for volumetric heat release, as well as data on pressure losses over a wide range of mass flow rates of the coolant from 0.05 to $1.75 \mathrm{~kg} / \mathrm{s}$ are obtained.
\end{abstract}

\section{Introduction}

Further increase of nuclear energy efficiency with simultaneous enhancement of security requires a conceptually new approach. One of the promising solutions of this problem is the use of alternative fuel rods in the form of spherical fuel elements. On the one hand FA MT have an inherent internal security, and on the other hand they will allow to improve energy efficiency.

The construction of the fuel assembly with microfuels was proposed in [1]. In such an assembly, the microfuels are placed between the perforated covers. To minimize the pressure losses, a cross flow of the heat coolant is realized. Fuel assemblies based on microfuels are likely to find application, primarily in low-power nuclear station.

\section{Experimental facility}

This paper is a continuation of the research presented at $[2,3]$. A low-pressure model installation with two test sections was designed and manufactured, with the possibility of simulating both single-phase and two-phase flow of the coolant in a pebble bed with volumetric energy release. The description of the hydraulic circuit is presented in [3].

\subsection{Test sections}

The central part of the test section No. 1 (Fig. 1a) modelling a cylindrical pebble bed consists of two coaxially arranged polycarbonate tubes $(1,2)$ with a diameter of 32 and

\footnotetext{
*Corresponding author: SmorchkovaYV@mpei.ru
} 
$50 \mathrm{~mm}$. The inner tube holds the pebble bed. The outer tube ensures the strength and tightness of the structure. The pebble bed is fixed by gratings (3) made of welded balls. The supply of coolant, the alignment of pipes and grids is carried out through the elements of the body frame (4), made of fiberglass. They also provide pressure sampling (6) and sealed feedthroughs (5) for thermocouples that measure the temperature profiles in the backfill and the temperature of the coolant at the inlet and outlet of the test section.

A detailed description of the test section 2 (Fig. 1b) is given in [3]. In this test section, pulse tubes for measuring the pressure drop were modernized. Earlier in [3], the measured pressure drop took into account the pressure losses at the inlet and outlet of the section. These losses made a significant contribution to the overall pressure loss. To exclude this effect, pressure taps have been transferred directly to the dispenser (1) and collecting receiver (5).

15 cable thermocouples are placed in the medium of the pebble bed. All of them are installed in 4 sections along the height of the pebble bed (T1-T15).

Pebble bed consists of balls with a diameter of $2.0 \mathrm{~mm}$ are made from steel grade AISI 420. The internal heat in the pebble bed is modelled by high-frequency induction heating by an inductor (7).

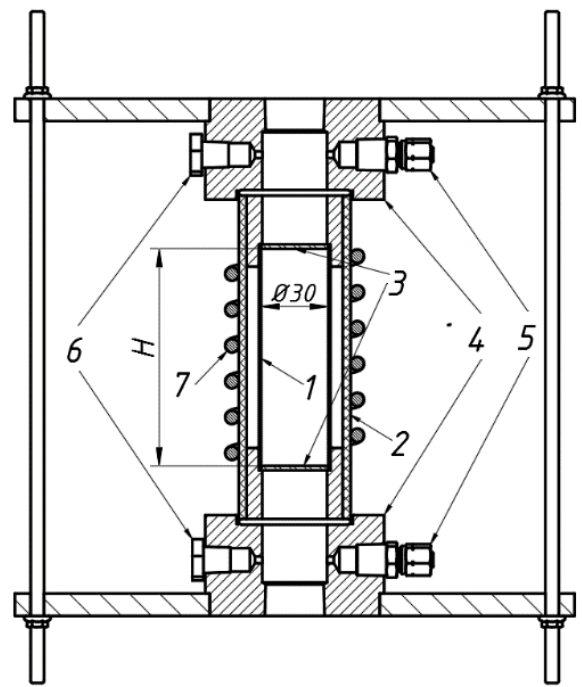

a)

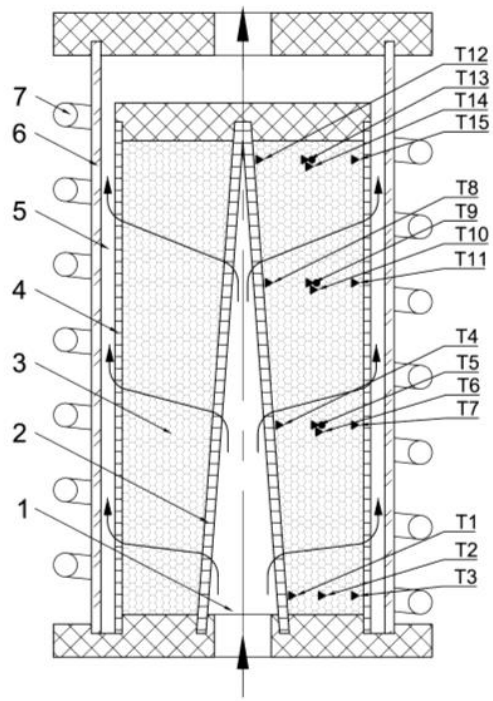

b)

Fig. 1. Test sections: a) pebble bed in the cylindrical conduit,

b) model of fuel assembly with microfuels

\section{Experimental data}

\subsection{Test section 1}

Experiments to determine the pressure losses for the pebble bed with a height of 100 $\mathrm{mm}$ were carried out in the range of mass flow rate of water from 0.50 to $1.75 \mathrm{~kg} / \mathrm{s}$ at a temperature of $25^{\circ} \mathrm{C}$. Fig. 2a shows the dependence of the coefficient of hydraulic resistance as a function of the Reynolds number. To generalize the obtained experimental data, the calculation formulas of Bogoyavlensky R.S. (1) and Avdeev A.A. (2) for the 
coefficient of hydraulic resistance have been applied, which had been published in [4] and [5], respectively.

$$
\begin{gathered}
\xi=\frac{0,54}{\varepsilon^{4}}\left(1+\frac{10}{\operatorname{Re}_{s t r}^{0,7}}+\frac{100}{\operatorname{Re}_{s t r}}\right) \\
\xi=\frac{1,53}{\varepsilon^{4,2}}\left(0,335+\frac{3}{\operatorname{Re}_{s t r}^{0,7}}+\frac{30}{\operatorname{Re}_{s t r}}\right), \quad \operatorname{Re}_{s t r}=\frac{0,45 \mathrm{Re}}{\sqrt{\varepsilon}(1-\varepsilon)}
\end{gathered}
$$

In formulas (1), (2), $\varepsilon$ is the porosity of the pebble bed, the Reynolds number Re is determined from the filtration rate and the diameter of the ball.

The temperature field along the height of the pebble bed, with a thermal capacity of 13 $\mathrm{kW}$ is shown in Fig. $2 \mathrm{~b}$. The points are obtained by averaging the values measured by the thermocouples located in one cross section. This temperature distribution over the height of the pebble bed does not contradict the physical concepts of the upward flows in pebble beds: the enthalpy of the coolant flow increases in height, while retaining the character of the temperature distribution.

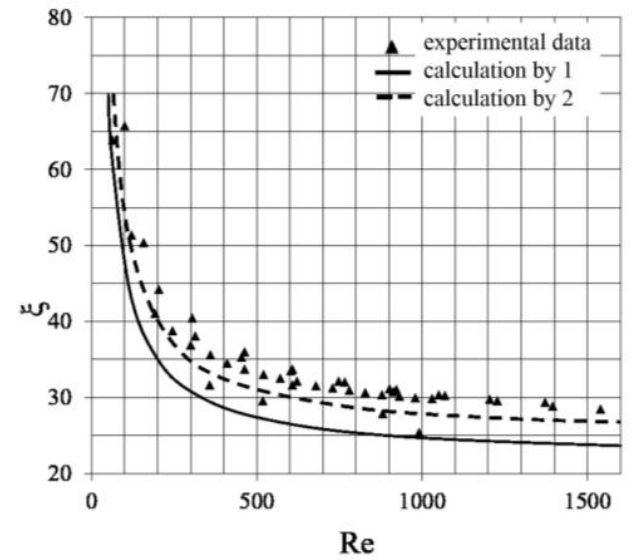

a)

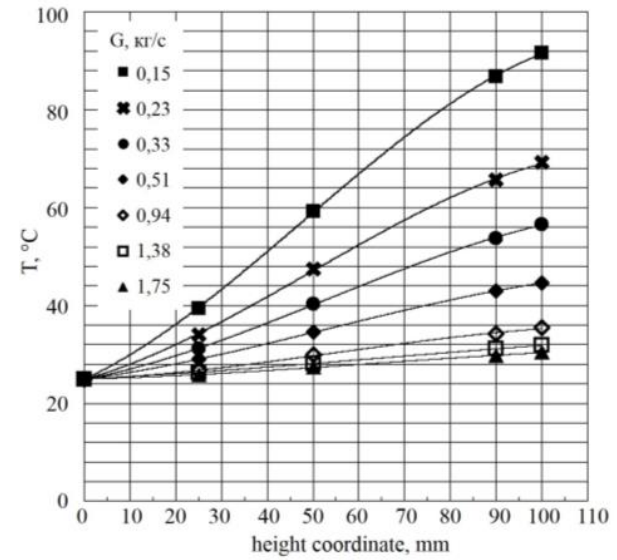

b)

Fig. 2. a) Dependence of the coefficient of hydraulic resistance on the Reynolds number,

b) Temperature distribution over the height of the pebble bed

\subsection{Test section 2}

The primary experimental data in the form of the dependence of the pressure loss on the mass flow rate are shown in Fig. 3a. Mass flow rate varied from 0.05 to $0.60 \mathrm{~kg} / \mathrm{s}$, the liquid temperature was maintained at $20^{\circ} \mathrm{C}$. To take into account the contribution of the inner and outer perforated covers to the total pressure loss in the test section, experiments were performed without the pebble bed. The results of these experiments are shown in the figure. Then, several series of experiments were performed with pebble bed at the same regime parameters. The results of the experiments are shown in Fig. 3a. There is good reproducibility of the results, the discrepancy between the data of different series does not exceed $10 \%$.

When comparing the data on pressure losses with pebble bed and without pebble bed, it can be seen that the largest contribution to the total pressure loss is made by perforated covers (up to $65 \%$ ).

To determine the degree of uniformity of heat release in the pebble bed, experiments were carried out with heating of the pebble bed without flow of the coolant. The results of 
the experiments in the form of the temperature dependence on the height coordinate of the pebble bed are shown in Fig. 3b. When analysing the data (Fig. 3b), there is a significant heterogeneity in the heating of the filling with respect to height. In the central part of the pebble bed, the temperature at different points varies within $5{ }^{\circ} \mathrm{C}$. At the same time, the difference in the temperature of the pebble bed in the central part and at the butt ends reaches $17{ }^{\circ} \mathrm{C}$. These differences are related to the features of induction heating. A similar effect is observed in the works of other authors, for example [6].

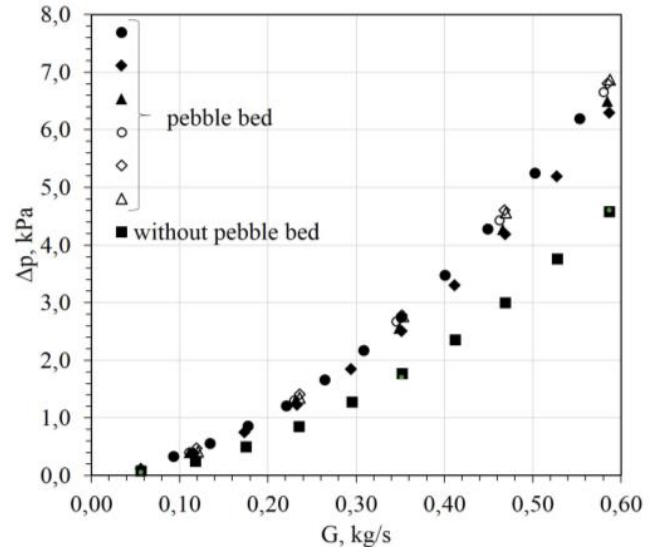

a)

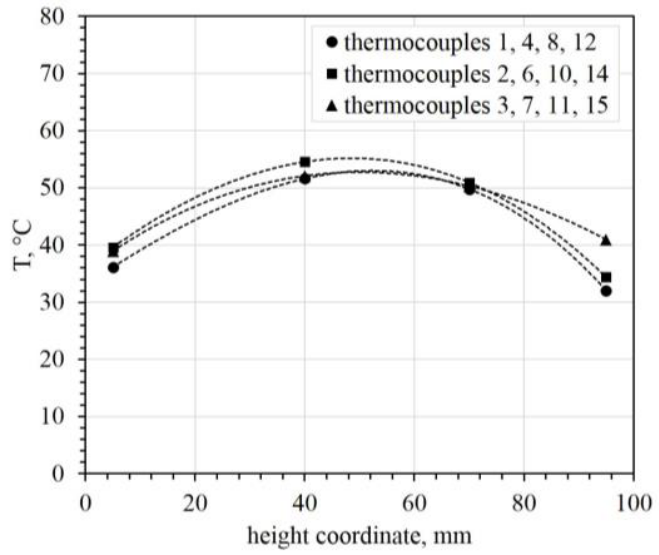

b)

Fig. 3. a) Dependence of pressure losses on mass flow rate

b) Temperature distribution over the height of the pebble bed

\section{Conclusion}

- For the first time experimental data on the thermohydraulic parameters on the FA MT model have been obtained;

- Experimental data on the flow in a cylindrical backfill supplemented and expanded the available data of other authors and confirmed the correctness of calculations using the empirical formulas $[4,5]$.

The work is supported RSF (grant № 16-19-10457)

\section{References}

1. N.N. Ponomarev-Stepnoy, N.E. Kukharkin, A.A. Khrulev, Y.G. Degaltsev., Nuclear Energy 86 443-449 (1999)

2. A.V. Borozdin, A.N. Varava, A.V. Dedov, A.T. Komov, S.A. Malahovskiy, Y.V. Smorchkova, Thermal processes in the engineering, 7, 295 (2015)

3. Y.V. Smorchkova, A.N. Varava, A.V. Dedov, A.T. Komov, J. Phys.: Conf. Ser., 754, 112008 (2016)

4. R.S. Bogoyavlensky, Atomizdat, Moscow, 112 (1978) [in Russian]

5. A.A. Avdeev, R.I. Soziev, G.A. Filippov, B.F. Balunov, R.A. Rybin, High Temp., 41, 377 (2003)

6. X. Meng, Z.G. Sun, G.Z. Xu, Nuclear Eng. Design, 252, 121 (2012) 